\title{
A Locally Secreted Thyrotropin Variant May Regulate Thyroid Function in Thyroid Inflammatory Disorders
}

\author{
Su He Wang ${ }^{1}$ and Ronald J. Koenig ${ }^{2}$
}

$\mathbf{T}$ HYROTROPIN or thyroid stimulating hormone (TSH) is a glycoprotein composed of noncovalently bound $\alpha$ - and $\beta$ subunits (1). The $\alpha$-subunit is common to the glycoprotein hormone family members lutropin, follitropin, chorionic gonadotropin, and TSH. The $\beta$-subunit is unique and confers specific immunogenic and hormonal functions. Classically, TSH is synthesized and secreted by the thyrotroph cells of the anterior pituitary, and its main function is to stimulate the production and secretion of thyroid hormones (thyroxine $\left[\mathrm{T}_{4}\right]$ and triiodothyronine $\left[\mathrm{T}_{3}\right]$ ) from thyrocytes. The secretion of TSH is in turn inhibited by circulating $\mathrm{T}_{4}$ and $\mathrm{T}_{3}$, forming a negative feedback loop to maintain the level of thyroid hormones within a narrow range. Cells outside the pituitary, including lymphocytes, also are capable of producing TSH (2-3), but the significance of this extra-pituitary hormone is unclear.

Vincent et al. (4) report the first example of a $\mathrm{TSH} \beta$ splice variant that results in the production of an alternate TSH $\beta$ protein. This splice variant was demonstrated in mouse tissues, so it is important to note that the murine Tshb gene has five exons and that the coding region is confined to exons 4-5. The splice variant transcript begins within the distal portion of intron 4; hence, it lacks the exon 4 codons but contains nine novel codons derived from intron 4 followed by the exon 5 codons. The predicted protein includes the distal 71\% of TSH $\beta$ and encompasses the region that interacts with the common $\alpha$ subunit. Secondary structure analysis suggests the novel first nine amino acids may function as a hydrophobic leader sequence, and transfection studies in Chinese hamster ovary cells confirmed that the $\mathrm{TSH} \beta$ variant protein is secreted. Furthermore, the TSH $\beta$ variant protein elicited a cAMP response when applied to TSH receptor-expressing cells in culture. Reverse transcription-polymerase chain reaction studies indicated that the splice variant transcript is preferentially expressed in mouse bone marrow cells and thyroid (it is presumed that bone marrow-derived cells migrating into the thyroid account for expression in that organ). Of additional potential interest, when mice were infected systemically with reovirus, splice variant transcript expression increased sevenfold in the thyroid.

This novel TSH $\beta$ variant has two important features in addition to its potential biological activity. First, the fact that it is generated from bone marrow cells suggests its production and secretion may not be subject to the negative feedback regulation of circulating $\mathrm{T}_{4}$ and $\mathrm{T}_{3}$. Second, up-regulation in the thyroid by systemic viral infection suggests the splice variant may influence $T_{4}$ and $T_{3}$ secretion in infection- or inflammatory-related thyroid disorders.

However, a number of questions remain. Although the authors demonstrate a cAMP response to this variant $\mathrm{TSH} \beta$ in cultured cell lines, there was not much of a dose-response effect and it is not known whether the variant can promote the production and secretion of thyroid hormone from the thyroid gland. If it can, the $\mathrm{TSH} \beta$ variant may contribute to thyroid hormone secretion in thyroiditis or systemic inflammation in a manner independent of negative feedback from the hypothalamic-pituitary axis. The exact nature of the bone marrow-derived cells producing the variant $\operatorname{TSH} \beta$ needs to be determined, as well as whether thyroid production of this variant is indeed from such cells. The authors do not examine whether the cellular source of variant $\operatorname{TSH} \beta$ also produces the common $\alpha$-subunit, which might allow it to function as an intact glycoprotein dimer rather than a monomer. Although the authors assume the variant is produced via alternative splicing, the data are compatible with a tissue-specific promoter within intron 4 driving expression of this transcript. Since these studies were performed in mice, it would be important to determine if a similar variant transcript is produced in humans. A comparison of the murine Tshb and human TSHB genes reveals that the novel amino acid sequence derived from intron 4 potentially could be produced from the human gene (i.e., the putative initiator ATG is conserved) and would be identical in seven of its nine residues. However, the $200 \mathrm{bp}$ of intron 4 sequences immediately preceding the start of the variant transcript, which might constitute a putative tissue-specific promoter, are not conserved in the human gene. Future studies no doubt will expand our understanding of this interesting $\mathrm{TSH} \beta$ variant.

\section{Disclosure Statement}

No competing financial interests exist.

\section{References}

1. Szkudlinski MW, Fremont V, Ronin C, Weintraub BD 2002 Thyroid-stimulating hormone and thyroid-stimulating

${ }^{1}$ Division of Allergy and Clinical Immunology, and ${ }^{2}$ Division of Metabolism, Endocrinology and Diabetes, University of Michigan, Ann Arbor, Michigan. 
hormone receptor structure-function relationships. Physiol Rev 82:473-502.

2. Smith EM, Phan M, Kruger TE, Coppenhaver DH, Blalock JE 1983 Human lymphocyte production of immunoreactive thyrotropin. Proc Natl Acad Sci U S A 80:6010-6013.

3. Harbour DV, Kruger TE, Coppenhaver D, Smith EM, Meyer III WJ 1989 Differential expression and regulation of thyrotropin (TSH) in T cell lines. Mol Cell Endocrinol 64: 229-241.

4. Vincent BH, Montufar-Solis D, Teng BB, Amendt BA, Schaefer J, Klein JR 2008 Bone marrow cells produce a novel
$\mathrm{TSH} \beta$ splice variant that is upregulated in the thyroid following systemic virus infection. Genes Immun Aug 28 [Epub ahead of print].

Address reprint requests to: Ronald J. Koenig, M.D., Ph.D. 5560 MSRB-2

1150 W. Medical Center Drive Ann Arbor, MI 48109-5678

E-mail: rkoenig@umich.ed 